\title{
Sen's Capability Approach to Welfare Economics
}

\author{
Wiebke Kuklys and Ingrid Robeyns
}

February 2004

CWPE 0415

Not to be quoted without permission 


\section{Sen's Capability Approach to Welfare Economics \\ Wiebke Kuklys ${ }^{1}$ \\ Ingrid Robeyns $^{2}$}

\section{Introduction}

Amartya Sen's capability approach is a framework for the evaluation of individual welfare and social states, and as such can provide the theoretical basis for inequality, poverty, and policy analyses. The capability approach assesses people's welfare in terms of their functionings and capabilities, which are defined as an individual's actual and potential activities and states of being respectively. When he started to develop the approach in the early 1980s, Sen found that while the (roughly equivalent) GNP per capita of Brazil and Mexico are more than seven times the GNP per capita of India, China and Sri Lanka, functionings performance in terms of life expectancy, infant mortality and child death rates were most favourable in Sri Lanka, and better in China compared to India and Mexico compared to Brazil (Sen [62]: 46-51). Although Sen used only three very basic functionings, he showed that ranking of countries based on GNP per capita can be quite different from the ranking based on the selected functionings. In another study he examined sex discrimination in India (Sen [62]: 52-69). He found, among other things, that females have worse achievements than

\footnotetext{
${ }^{1}$ University of Cambridge and Max Planck Institute for Research Into Economic Systems, Jena, Germany. Correspondence to kuklys@mpiew-jena.mpg.de. Support from the ESRC (Ref.Nr. 42200034240) is gratefully acknowledged.

${ }^{2}$ University of Amsterdam, Netherlands, and Columbia University, USA (visiting 2004). Correspondence to i.robeyns@uva.nl. Support from the Netherlands Organization for Scientific Research (NWO) is gratefully acknowledged. Both authors wish to thank Paul Anand, John Davis, Werner Güth, Geoff Harcourt, Hamish Low, Stephan Klasen, Melvyn Weeks and an anonymous referee for comments on earlier versions. The usual disclaimer applies.
} 
males for a number of functionings, including age-specific mortality rates, malnutrition and morbidity. Since 1990, the United Nations has adopted the basic ideas of the capability approach in its annual Human Development Reports (Fukuda-Parr [23]), which measure the state of development of a country by analysing people's life expectancy at birth, education (measured by adult literacy and educational enrolment rates), and adjusted real GDP per capita, which should serve as a proxy for the material aspects of welfare. Comparisons of rankings of these indices with GNP per capita shows significant differences (UNDP [70]). Although these indices are generally regarded as a crude application of the capability approach, they have significant political influence.

Sen's capability approach has also found wide resonance in a number of academic disciplines, including heterodox economics (Fukuda-Parr [23], Gasper [26], Robeyns, [56]), development economics (Alkire [1], Qizilbash [54]), development ethics (Crocker [20], Gasper [25]) and economic and political philosophy (Daniels [21], Nussbaum [47], Pettit [51], Williams [71]). This literature is characterised by its highly interdisciplinary nature and the predominance of philosophical and conceptual reasoning instead of modelling and formalisations. The impact and development of the capability approach in mainstream welfare economics has so far been much more limited, a few exceptions notwithstanding (Atkinson [3], Basu and López-Calva [10], Maasoumi [43]). There are several ways in which this could be explained. It might be the case that the capability approach is 'old wine in new bottles', and has very little to offer to welfare economics. If this were true, then why would welfare economists pay any attention? Another possible explana- 
tion is that most of the work on the capability approach has been written in a jargon and disciplinary style that is too philosophical to be appealing to most economists. Or alternatively, the fact that there is no consensus on how to apply the capability approach might be off-putting. To determine whether the capability approach has something to offer to standard welfare economics we need a characterisation and analysis of the capability approach using the methodology and language standardly employed in welfare economics. That is the aim of this paper.

We first briefly describe the capability approach and present a formalisation (section 2). Then we define standard welfare economics and present a basic model in section 3. In section 4 , the assumptions of this model are scrutinised from a capability perspective. This allows us to understand better whether the capability approach represents a genuine theoretical alternative to the standard welfare economic model. In addition, we not only need a theoretical comparison of the standard welfare economic model with the capability approach to welfare economics, but we also need to know to what extent the capability approach makes a difference in terms of empirics. This question is addressed in section 5 where we provide a survey of the quantitative empirical applications of the capability approach. The last section concludes.

\section{Sen's Capability Approach}

The capability approach is an evaluative framework for individual welfare and social states. The core concepts are functionings and capabilities. Sen ( [66]:5) defines functionings as an achievement of a person, i.e. what he or she 
manages to do or to be: an individual's activities and states of being. Capability is a derived notion, and reflects the various combinations of functionings he or she can achieve, i.e. the person's freedom to choose between different ways of living.

In traditional economic welfare evaluation, particularly in the context of poverty and inequality, income or expenditure is analysed. In the capability approach, an evaluation involves the analysis of a capability set, $Q_{i}$, which is defined over the different potential activities or states of being $\mathbf{b}$ of individual $i$

$Q_{i}\left(X_{i}\right)=\left\{\mathbf{b}_{i} \mid \mathbf{b}_{i}=f_{i}\left(c\left(\mathbf{x}_{i}\right), \mathbf{z}_{i}\right) \quad \forall f_{i} \in F_{i}\right.$ and $\left.\forall \mathbf{x}_{i} \in X_{i}\right\}$

where $\mathbf{x}_{i}$ is a vector of commodities chosen by the individual, $c(\cdot)$ is a function that maps goods into the space of characteristics as in Gorman [29] and Lancaster [39], $\mathbf{z}_{i}$ is a vector of personal characteristics and societal and environmental circumstances, $f_{i}$ is a function that maps characteristics of goods into states of being or activities $\mathbf{b}_{i}$, conditional on $\mathbf{z}_{i}$. $Q_{i}$ is the set of all possible $\mathbf{b}_{i}$, given the resource constraint $X_{i}$ (Sen [62]:7-10).

The vector of commodities $\mathbf{x}_{i}$ is the demand for goods. Note, however, that Sen explicitly includes non-market goods and services. Similarly, resources $X_{i}$ correspond to the standard budget constraint, but also include the availability of non-market goods and services.

The space of functionings $\mathbf{b}$ is the space of states of being and activities, while the space of capabilities $Q$ is the space of potential functionings. The functioning space is related to the goods and characteristics space through the personal conversion function $f_{i}$. The capability space is related to 
the functioning space in that it comprises all functionings an individual can potentially achieve. It is thus the individual's choice set, and could be interpreted as an augmented budget set, which also takes account of non-market goods and services, and non-monetary constraints.

Two examples are discussed by Sen [62]. A bicycle (commodity $x$ ) provides transport (characteristic $c$ ); and depending on an individual's physical ability and the state of the roads (conversion factors $\mathbf{z}$ ), she can cycle or not (capability $Q$ ). Food provides nutritious capacity, which is converted into 'being well-nourished', depending on physical circumstances such as the metabolic rate, presence of parasites etc.. The individual's capability includes then the freedom to either be well-nourished, to fast for religious reasons or to go on hunger strike for another's sake.

Other examples of functionings, taken from Sen [65] are 'being alive', 'being in good health', 'being well-sheltered', 'moving about freely', 'having self respect and respect of others', 'taking part in the life of the community'. One could add many other functionings, such as 'being employed' or 'being educated'.

The capability approach clearly operates at two levels: at the level of realised welfare, which is measured by functionings; and the level of potential or feasible welfare, which is measured by capabilities. This is equivalent to the outcomes vs. opportunities distinction in standard welfare economics and especially in social choice theory. 


\section{Characterisation of Welfare Economics and its Tools}

In this section, we offer a characterisation of welfare economics and present a benchmark model. Our aim is to briefly outline the field of welfare economics before we scrutinise it in light of the capability approach in section 4 .

\subsection{Definition and Characterisation}

Welfare economics is concerned with the evaluation of the level of individual and social welfare, and the welfare impact of economic and social policies (see e.g. Dutta [22], Sen [63] and Suzumura [68]). The welfare of individuals is represented by utility, usually understood as desire fulfillment or preference satisfaction. Although there is some debate on the exact properties and characterisation of the notion of utility, there is general agreement that utility as used in economics is a one-dimensional concept. In applied welfare economics, utility is routinely measured by monetary variables. This is only valid under restrictive assumptions about the individual and the market, which will be discussed in section 4 .

Social welfare is an aggregation of the individual welfare by means of an aggregator function which can be interpreted as a social welfare function. Social welfare functions can have different forms, implying that some of them will take distributional considerations into account while others will not. If the social welfare function is the maximisation of the unweighted sum of the individual welfares, then it is a utilitarian social welfare function.

Most research in welfare economics uses individual utilities (in applications, income or expenditure) as the ex- 
clusive basis of welfare judgements. This tradition, which has been dominant for the last two centuries, is called welfarism [61]. However, in recent decades several important departures from welfarism have been made, by including non-utility information in the evaluation of individual welfare. Pattanaik [48] distinguishes between two broad areas of non-welfaristic research in welfare economics. The first area is the work on individual rights and liberties, which was pioneered by Sen's work on the liberal paradox (Sen [59], [60]). The second area concerns the measurement of the standard of living, inequality and poverty whereby the information used is not restricted to utility or a monetary representation thereof. It is in this second line of departure from welfarism that the capability approach can be situated. In section 4 , we will analyse welfare economics from a capability perspective, but first we present a simple formalisation of standard welfare economics.

\subsection{The model}

Let us take as point of departure the basic textbook model for welfare evaluation in a many consumer market economy where all consumers face the same consumption prices. Assume an economy without uncertainty, with $n$ identical utility maximising consumers, who can all choose among a vector of goods $\mathbf{x}$, and who are subject to a budget constraint:

$$
\max u_{i}=u(\mathbf{x}) \quad \text { subject to } \mathbf{p} \cdot \mathbf{x}=m_{i} \quad i=1, \ldots n
$$

where $m$ is the exogenously given income, and $\mathbf{p}$ is a vector of market prices corresponding to goods $\mathbf{x} . u_{i}$ is individual $i$ 's utility, $n$ is the number of individuals under analysis. $u$ is the individuals' continuous and differentiable utility 
function, for which $\frac{\partial u(\mathbf{x})}{\partial \mathbf{x}}>0$. The indirect utility function $v$ can be written

$$
v_{i}=v\left(\mathbf{p}, m_{i}\right) .
$$

The level of indirect utility can be measured by the individual's income if all individuals have the same preferences and face the same prices. Assuming prices to stay constant, the impact of social and economic policy on an individual's welfare can be evaluated by

$$
d v_{i}=\frac{\partial v}{\partial m_{i}} \frac{\partial m_{i}}{\partial \pi}
$$

where $\pi$ is the implemented policy.

In this model, overall social welfare $W$ is an aggregate of the individuals' utility. This is expressed by the social welfare functional $G$,

$$
W=G\left(v_{1}\left(\mathbf{p}, m_{1}\right), \ldots, v_{n}\left(\mathbf{p}, m_{n}\right)\right) .
$$

Social welfare functions comprise, for example, a large class of inequality and poverty indices.

Social welfare functions are also used as a tool for policy analysis. Under differentiability, continuity, separability and cardinality assumptions, the social welfare functional $G$ can be used to calculate welfare change stemming from a small change in income, namely

$$
d W=\sum_{i=1}^{n} \frac{\partial W}{\partial G} \frac{\partial G}{\partial m_{i}} d m_{i}=\sum_{i=1}^{n} \beta_{i}\left(m_{i}\right) d m_{i},
$$

where $\beta_{i}\left(m_{i}\right)$ corresponds to the marginal social utility of income $m_{i}$. If the marginal social utility of income is assumed to be constant and equal across individuals, it can be normalised to $\beta_{i}=1$, and $G$ corresponds simply to the 
sum operator, so that

$$
d W=\sum_{i=1}^{n} d m_{i}
$$

The overall welfare change owing to a change in individual incomes then corresponds to the sum of these changes; this would correspond to a utilitarian analysis of welfare changes induced by the implementation of a policy.

\section{Welfare Economics Revisited}

In the light of the capability approach, we will now take a second look at this model. We want to analyse in which way Sen's approach is an extension of this model, and to what extent this is different from other strands of research within welfare economics. The core critique offered by the capability approach is the exclusive use of utility, which is represented by income or expenditure as the measure of welfare. More specifically, there are three problems with the use of income: the omission of the impact of non-market goods and services on the individual's welfare; secondly, a disregard of interpersonal heterogeneity in converting income into welfare, particularly in poverty and inequality analysis; and thirdly, the neglect of the intrinsic value of choice.

To analyse this critique in detail, we examine the benchmark model's assumptions on market and individuals. We give a brief account of the criticisms offered by the capability approach, and formalise this criticism in the language of the textbook model. We then present recent research in welfare economics, and assess whether the capability approach offers a genuine alternative to the existing frame- 
work. To reflect the recent advances in welfare economic research adequately, we distinguish between the measurement of individual welfare levels along the lines of equation (3) and the evaluation of changes in welfare induced by economic and social policies as in equation (4). This distinction is made because our analysis will show that both types of research are to a different degree vulnerable to the capability critique.

\subsection{The Market}

The individual utility function and the budget constraint in equation (2) are defined over a composite good, or in a slightly more complex model, over a vector of goods and services which can be bought in the market. In the basic model, it is assumed that all consumers face the same consumption prices, that there are neither externalities nor public goods and that all goods are always available. Many economists, including Sen, have pointed out that not all objects over which an individual's preferences are defined are marketable. The market might be subject to imperfections such as externalities or rationing, or simply not provide certain goods and services at all. For example, the income of individuals living close to a polluting factory is not compensated for the effect of the pollution on their welfare. The cost of hiring an elderly care worker is not necessarily equivalent to the welfare effect of care by loving relatives.

One could, in principle, include externalities and other non-market goods and services into the benchmark model. These extensions could be introduced ceteris paribus into the model by defining the utility function in (2) over a range of market consumption goods $\mathbf{x}$, the average consumption of these goods, $\overline{\mathbf{x}}=\sum_{i=1}^{n} \mathbf{x}_{i}$, a public good $x^{p g}$, a rationed 
good $x^{r}$ and a good which is not buyable in the market $x^{n m}$ so that for $i=1, \ldots, n$

$$
\begin{aligned}
\max u_{i} & =u\left(\mathbf{x}, \overline{\mathbf{x}}, x^{p g}, x^{r}, x^{n m}\right) \quad \text { subject to } \\
\mathbf{p} \cdot \mathbf{x} & =(1-t) m_{i} \\
x^{r} & =\underline{x}^{r} \\
x^{n m} & =\underline{x}^{n m} \\
x^{p g} & =\sum_{i=1}^{n} t m_{i}
\end{aligned}
$$

where $t$ is the tax rate, $\underline{x}^{r}$ and $\underline{x}^{n m}$ are the available amounts of the rationed good and the non-market good respectively, $\frac{\partial u}{\partial \mathbf{x}}>0$ as before, $\frac{\partial u}{\partial \overline{\mathbf{x}}}>0$ if the good has a positive externality, $\frac{\partial u}{\partial \overline{\mathbf{x}}}<0$ if it has a negative externality, and $\frac{\partial u}{\partial \overline{\mathbf{x}}}=0$ if there is no externality; further, $\frac{\partial u}{\partial x^{p g}}>0, \frac{\partial u}{\partial x^{r}}>0, \frac{\partial u}{\partial x^{n m}}>0$.

Of course the basic model in section 3.2 generally does not reflect current research on evaluating the effect of policy induced changes on individual welfare. In research specifically focussing on public goods (see, e.g. Garber[24]), nonmarket goods (see e.g. Train, Goett and Hudson [69] Gayatri and Bunnet, [27]) on externalities, the measurement of the welfare impact of policies, as modelled in equation (4), takes these additional complexities into account..

However, if the focus of research is not on welfare change induced by policies, but on measurement of individual welfare levels as used in poverty or inequality analysis, Sen's critique has bite. The money metric utility function in equation (3) can, strictly speaking, only be used to represent an individual's welfare in terms of utility if the market assumptions hold, which is generally not the case. Nevertheless, routinely income or expenditure is used as the best possible approximation of an individual's utility (see 
e.g. Atkinson and Bourguignon [6]). Inequality and poverty analysis (based on equation (5)) as well as project analysis (based on equation (6)) hence disregard non-monetary sources of welfare and non-monetary constraints to decision making (see e.g. Cowell [18], Goodman, Johnson and Webb [28] and Harberger [30]).

One way to avoid potential bias in individual welfare measurement as a consequence of this disregard is to use the expanded utility function in equation (7) as the underlying model. Analogue to equation (3), an extended indirect utility function $v^{e x t}$ can be derived for individual welfare measurement in money metric terms:

$$
v_{i}^{e x t}=v\left(\mathbf{p}, p_{i}^{*}, p_{i}^{p g}, p_{i}^{r}, p_{i}^{n m}, m_{i}\right)
$$

where $p_{i}^{*}, p_{i}^{p g}, p_{i}^{r}, p_{i}^{n m}$ are the shadow prices (individual valuations) of the good with externality $\bar{x}$, the public good, the rationed and the non-market good respectively.

Considering the difficulties with welfare measurement and functional forms in the simple model in section 3.2, it is no surprise that equation (9) is not the route chosen by researchers who would like to take account of rationing, non-market goods, public goods and externalities in welfare measurement. Measurement of shadow prices of goods whose market prices do not reflect their marginal utilities is in general difficult. Measuring indirect utility according to (9) for each individual in a society as an input to inequality or poverty analysis would imply a prohibitive effort, if it were at all possible. Instead, economists recently have begun to study inequality and poverty in terms of other variables than income; they study outcome variables $d i$ rectly. We will review this literature in section 5 , but first we analyse the capability critique of the assumptions about 
the individual in the standard model.

\subsection{The Individual}

The assumptions made in the basic model about the individual can be considered in terms of behavioural assumptions on the one hand, and assumptions about the individual's preferences and her utility on the other. The behavioural assumptions include that the individual takes decisions based on utility maximisation (equation (2)). In the basic model, this implies that, subject to her budget constraint, an individual chooses the basket of goods which maximises her satisfaction or pleasure. The second class of assumptions about the individual in the benchmark model of section 3.2 include that the utility achieved is independent of the non-chosen goods or services. Furthermore, there is no intrinsic value attached to the act of choice. Another important assumption is that individuals have the same preferences and needs; in other words, individuals only differ in terms of their budget constraint.

Sen questions all of these assumptions. In what follows, we will not examine Sen's critique of maximising behaviour, as this critique is independent of whether welfare is defined in terms of utility, income or capability (Sen [64]). Instead, we focus on the assumption of irrelevance of the intrinsic value of choice, and the assumption of constant preferences across individuals.

\subsubsection{Intrinsic Value of Choice}

Sen [62] suggests that individuals derive utility both from the range of options in the choice set, as well as from the possibility to perform the act of choice themselves. Com- 
pare the following three choice sets: $A=\{a\}, B=\{a, b\}$ and $C=\{a, b, c\}$ with a, $\mathrm{b}$ and $\mathrm{c}$ not identical and the range in $\mathrm{C}$ is larger than in $\mathrm{B}$ than in $\mathrm{A}$. The individual prefers $a$ over $b$ and $c$. In standard welfare economics individual $i$ 's utility derived from the sets $A, B$, and $C$ is the same. However, Sen argues that the loss of freedom of choice in $B$ compared to $C$ and $A$ compared to $B$ should be reflected in individual $i$ 's welfare. The intrinsic value of choice consists of two components: the act of choosing itself (absent in $A$, present in $B$ and $C$ ) and the range of valued options (largest in $C$ ). This critique has triggered a large literature on the ranking of sets in social choice theory and non-welfarist welfare economics, which started with Pattanaik and $\mathrm{Xu}$ [49].

Of course welfarism could be interpreted as being sensitive to some of these aspects. If the act of choice itself would generate utility, then being able to choose from $B$ will generate more total utility for individual $i$ than $A$, even though the utilities derived from the option that is picked alone $(a)$ will be the same. The problem thus lies in the fact that welfare economics in general does not compare the utility generated by having option set $A$ or $B$, but instead compares the option picked from $A$ or $B$. Similarly, welfarism could take account of some welfare consequences of the range of the choice set. For example, a person who chooses a certain chocolate bar among five alternative bars might derive more utility from this chocolate bar than a person who could not choose. Alternatively, a further brand of dishwashing liquid might make the decision making process among these liquids more difficult and hence produce disutility for the decision maker. But while the latter situation is sometimes modelled as a disutility provoked by information costs, the earlier finds no echo in welfare economics. 
In contrast, the capability approach, by distinguishing between functionings and capabilities, can account for both welfare derived from the chosen outcome (i.e. functionings) and welfare derived from the opportunity or choice set (i.e. capability).

\subsubsection{Preferences and Needs across Individuals}

Sen disputes the validity of the assumption that individuals have the same preferences and needs. As we have seen, he formalises this by means of a conversion function, which converts resources into functionings, with the conversion rate depending on personal, societal and environmental factors. When utility is defined over market goods as in the basic model, and consumers face the same prices, different levels of utility can only be derived from different levels of income. However, when utility is defined over functionings, different levels of utility can be derived either from different levels of resources or from different capacities to turn resources into functionings. We will call this latter difference in conversion factors the heterogeneity of needs. In line with the capability approach, we will assume that this difference is relevant for social welfare evaluation. At present, extensions of the basic model sometimes allow for differences in utility functions across individuals. However, since these utility functions are defined over goods, they confuse differences in the utility function with differences in the conversion function. In other words, these extensions conflate preferences with needs.

This notion of heterogeneity of needs could be formalised within the basic model by defining the utility function over outcomes $\mathbf{o}$, which are in turn a function of goods, and conditioning it on a vector of conversion factors, $\mathbf{z}$, e.g. 
disability, public infrastructure, intelligence etc.. Hence, equation (2) becomes

$$
\max u_{i}=u(\mathbf{o}(\mathbf{x}, \mathbf{z})) \quad \text { subject to } \mathbf{p} \cdot \mathbf{x}=m_{i} \quad i=1, \ldots n
$$

These outcome functions o (which differ from functionings because non-market goods and services are not included in the resource constraint here) have parallels in existing welfare economics research, as early as in Becker's ([11]) reformulation of consumer theory (commodity production function in the household) and in Atkinson and Stern's activities model ([7]). While Becker (see also Becker and Stigler [67]) insists that preferences are stable and equal across individuals, Aktinson and Stern accept the need to control for heterogeneity of expenditure patterns by including socio-demographic variables in their regressions.

This is in line with empirical research in policy evaluation, where heterogeneous preferences are routinely modelled by conditioning the estimations on a range of sociodemographic characteristics. However, such techniques only allow for a crude differentiation in preferences and needs across demographic subgroups. This literature has recently been enhanced: for example, the importance of differential responses to policy because of heterogeneous preferences is analysed by Browning, Hansen and Heckman [16] and Heckman [31]. Yet, despite this improvement, this research is still not abe to disentangle preferences and needs.

In the measurement of individual welfare levels, as used in inequality and poverty measurement, individual heterogeneity hardly plays a role: equivalence scales accounting for differences in size and composition across households are the only way in which heterogeneity is taken into account. 
While the methods of estimating such scales are becoming more and more sophisticated (Bellemare, Melenberg and van Soest [12], Cowell [19], Murti [46]), they concentrate only on assessing the additional cost that children present to a household. Jones and O'Donnell [33], Kuklys [36] and Zaidi and Burchardt [72] estimate equivalence scales in the presence of disabilities, thus taking into account one additional type of needs. However, equivalence scale estimation can only account for a small amount of heterogeneity, both for econometric reasons (taking account of more heterogeneity reduces the cell size on which the estimations are based) and data limitations (household surveys provide only a small set of needs indicators). In addition, the sources of individual heterogeneity can be either voluntary choices or exogenous differences, but the equivalence scale technique assumes that all heterogeneity is exogenous and breaks down if heterogeneity is the consequence of voluntary choice (see Pollak and Wales [53]).

Summing up, heterogeneity of utility functions is recognised in standard welfare economics, although the extent to which these interpersonal differences are incorporated in welfare analyses differs considerably between policy evaluation on the one hand and inequality and poverty measurement on the other. Moreover, the degree to which heterogeneity can be accounted for by equivalence scales is limited both for econometric and theoretical reasons.

\subsection{The capability approach - a genuine alternative?}

When combining our analyses of the assumptions of markets and individuals, an appropriate measure of an individual's welfare would be a further extension of equation 


$$
v^{e x t}=v\left(\mathbf{p}, p_{i}^{*}, p_{i}^{p g}, p_{i}^{r}, p_{i}^{n m}, m_{i} ; \gamma\left(\mathbf{z}^{i}, \mathbf{z}^{s}, \mathbf{z}^{e}\right) ; \text { choice }_{i}\right),
$$

where $\mathbf{z}^{i}, \mathbf{z}^{s}, \mathbf{z}^{e}$ are vectors of personal, societal and environmental factors that affect the conversion of available resources into outcomes. The variable choice $_{i}$ reflects the intrinsic value put by the individual on the freedom to choose. Evaluation of the effects of a policy $\pi$ could then be performed by analysing $d v^{e x t}=\frac{\partial v^{e x t}}{\partial \pi} d \pi$.

In the previous section we have seen that research on public goods, externalities and much policy research uses shadow prices and takes into account some of the individual heterogeneity implied by equation (11). On the other hand, poverty and inequality research is still confined to the analysis of household incomes or expenditure, albeit adjusted for household size.

The appropriate measurement of individual welfare levels as money metric utility according to equation (11) will be extremely difficult. It not only requires the estimation of shadow prices for each individual for each public, rationed or non-market good she has preferences for, but also the elicitation of the value of choice, and taking account of the conversion factors.

The question is whether it is easier to measure individual welfare levels by measuring functionings or capability sets directly. To shed light on this question, we will now review the applied research on welfare measurement and policy evaluation specifically dealing with the capability approach. 


\section{Evidence on the Measurement of Functionings and Capabilities}

So far we have only discussed theoretical critiques of the capability approach of standard welfare economics. In this section we will review existing applications, and analyse the methodologies employed and the difficulties faced in such applications. In particular we want to investigate whether measurement of functionings and capabilities makes a significant difference relative to the traditional welfare measurement in terms of income or expenditure. In section 5.1 we focus on the methodological issues involved in the measurement of functionings, i.e. the assessment of vector $\mathbf{b}_{i}$. Section 5.2 reviews the applied literature on the measurement of welfare levels as used in poverty and inequality analysis, and section 5.3 discusses the literature on policy evaluation $\frac{\partial \mathbf{b}}{\partial \pi}$.

\subsection{Methodological Issues}

In the empirical literature on the capability approach, four main methodological problems are addressed: the selection of the relevant functionings, the measurement of these functionings on the individual level, the aggregation of these functionings into a composite (scalar) measure of individual welfare and finally, the aggregation of individual welfare to societal welfare, e.g. an inequality or poverty index.

\subsubsection{Selection of Relevant Functionings}

Firstly, in most empirical contributions the selection of functionings is done in an ad hoc way, in accordance with the researchers' values (see for example Klasen [34] and Chiappero Martinetti [45]). In a number of instances (see, for 
example, Schokkaert and Van Ootegem [58], Lelli [40] and Balestrino and Sciclone [9]), a wide range of potentially relevant variables from household surveys are submitted to exploratory factor analysis to 'let the data decide' which are the relevant functionings. Here, the factor scores resulting from this analysis are used as the functionings representing an individual's welfare.

Robeyns [57] has developed a methodology for selecting relevant dimensions in a less ad hoc way. She proposes that the selection of functionings or capabilities would be structured along a number of methodological criteria. These criteria would require making the selection as explicit as possible, justifying the selection method used, making the selection sensitive to the context, distinguishing between different levels of generality, and achieving an as complete selection of functionings as possible. If the capability approach is not applied to the analysis of a large data set (i.e. a country-wide assessment of individual welfare), but instead is focussed on a local situation with few affected individuals, then participatory methods can be used, as has been done by Alkire [1]. The participatory method allows the affected individuals to decide which are the functionings relevant for their welfare.

\subsubsection{Measurement of Functionings at the Individual Level}

The measurement of functionings at the individual level entails two problems. First, assigning a number to achieved levels of functionings, and secondly, aggregating functionings to a composite (scalar) measure of individual welfare. In traditional money-metric analysis, measurement of individual welfare levels is relatively straightforward. Welfare is derived from goods only, and since the relative market 
prices of these goods represent the individual's relative valuation of the goods in terms of utility, these prices can be used to aggregate goods to a composite measure of individual welfare, i.e. the budget constraint. This is conveniently expressed in currency units, which can be compared among individuals and used in poverty or inequality analysis. In contrast, functionings measurement and aggregation is more difficult, because there is no established measurement scale for functionings, nor do there exist relative valuations between functionings which could be used for aggregation that are generally accepted and well-established.

At this stage, there is no consensus how to address this problem. Factor analysis is often applied to a range of variables available in household surveys. This has the two-fold advantage of reducing the number of functionings, e.g. by combining several variables such as humidity in dwelling or household members per room into a functioning 'being well-sheltered' and assigning numbers to the achieved level of each functioning. The use of factor analysis entails several problems. First, if the observable variables submitted to this analysis are measured on different scales, the factors might pick up method effects rather than substantive variance effects: if health problems are measured by a $0-1$ indicator, and dwelling problems on a Likert scale from 1 to 5, factor analysis might extract two factors because of this difference in measurement scale, not because there are substantive differences in variance. Second, this research routinely imposes orthogonality on the factor scores, which might blur the fact that the underlying functionings are actually correlated. For example, there is no reason why the functionings 'being healthy' and 'being well-sheltered' could not be correlated. It is questionable that if the func- 
tionings are correlated, orthogonal factors would represent adequately an individual's welfare. The third problem is that different variables (e.g. housing indicators) are aggregated to a functioning (being well-sheltered) by statistical weights. There is no reason why these weights should reflect the researcher's values or the individual's subjective valuation (relative prices) of the different variables. Finally, standard factor analysis as employed in these applications is not appropriate for dealing with ordinal variables, or for testing whether the implied model is adequate for the data.

An extension of confirmatory factor analysis are covariance structure models, employed in the capability context by Kuklys [35]. While variables are still combined into functionings by statistical weights, these models can be adapted to take into account ordinality of observed variables and allow testing for model adequacy in a statistical framework.

A different method, which avoids the problem of statistical weights to a certain extent is scaling, or an extension of it, the use of fuzzy sets. Scaling, i.e. a projection of each variable into a 0-1 range, was employed in the first major operationalisation of the capability approach, the human development index [70]. Chiappero Martinetti [45] pioneered the use of fuzzy sets theory in this area. The first step in fuzzy sets theory is to scale the variables into a $0-1$ interval. In a second step, several variables (e.g. health indicators) can be aggregated by different set operators $(\cap, \cup$,etc.) to a single functioning (e.g. 'being healthy'). This method allows the researcher to explicitly impose her value judgments on the aggregation. She can decide in which way the different indicators are considered to be complements or substitutes to each other, for example.

For comparison of a welfare measure based on function- 
ings with a traditional money metric measure, a composite welfare measure has to be calculated. Factor analysis and fuzzy sets can be used to aggregate functionings to a scalar individual welfare measure. In this context, Klasen [34] has used principal components analysis. The human development index is calculated by simply averaging the scaled functionings. Hirschberg, Maasoumi and Slottje [32] have used time-series clustering to aggregate different functionings. Maasoumi ([41], [42]) has worked extensively on the information theoretical and axiomatic underpinnings of multidimensional welfare analysis. He derives an optimal aggregator function for the different functionings by minimising the distance between the distributions of the composite measure and those of each functioning. Together with Nickelsburg [44], he has applied this approach to welfare analysis in the US. It is also possible not to work with a composite welfare measure but analyse the relationship of income with each functioning individually (see e.g. Chiappero Martinetti [45], Lelli [40] Robeyns [56]).

\subsubsection{Aggregation across Individuals}

To assess social welfare it is necessary to aggregate individual welfare to an overall social welfare measure, e.g. an inequality or poverty index. While the primary literature on the capability approach is not explicit about how to do this, the issue has to be faced inevitably if the capability approach is used for empirical inequality or poverty analysis. In principle, two possibilities exist in a multidimensional setting: using a composite measure as discussed in the previous paragraph in standard unidimensional inequality or poverty indices, or using the functionings in a multidimensional inequality or poverty analysis. Maasoumi 
and Nickelsburg and Brandolini and D'Alessio [15] have used multidimensional inequality indices, while Atkinson and Bourguignon ([4], [5]) have prepared the way for multidimensional stochastic dominance rankings of functionings distributions. Bourguignon and Chakravarty addressed the issue of multidimensional poverty indices [14] and multidimensional poverty (stochastic dominance) orderings [13].

\subsection{Measurement of Welfare Levels}

Let us now turn to a review of the quantitative empirical applications of poverty and inequality measurement. Table 1 (at end of paper) lists the studies and describes the datasets used, the functionings that were analysed, and the main findings.

The studies listed in Table 1 illustrate that the capability approach can be applied to investigate diverse questions, and at different levels of aggregation. At the highest level of aggregation, as in the first study by Sen ([62]: 46-51), and the work of the UNDP ([70]), the capability approach is applied to data at the national level. While such data represent aggregates and are arguably crude, they can reveal interesting insights when compared with GNP per capita. Sen's other early study ([62]: 52-69) used Indian data at different levels of aggregation to investigate gender biases. Over the last two decades, this kind of quantitative research based on aggregate data has become widespread, especially in development studies. Other studies use data at the provincial or regional level, such as those by Balestrino and Sciclone [9] and Qizilbash [55]. Still other applications do not rank regions or countries, but measure levels of welfare directly based on micro-data (Schokkaert and Van Ootegem [58], Balestrino [8], Ruggeri Laderchi [37], [38], Phipps [52], 
Chiappero-Martinetti [45], Klasen [34] and Lelli [40]. All these papers measure functionings, and not capabilities. As far as we are aware, there are only three attempts so far to (partially) measure capabilities or self-perceived capabilities instead of achieved functionings (Burchardt and Le Grand [17], Anand and van Hees [2], and Anand, Hunter and Smith [50]). Nevertheless, it should be noted that many capabilities that have theoretically been argued to be relevant are not sufficiently covered in the datasets used in these studies (like the BHPS), or are even not included at all. Needless to say that a lot of work remains to be done in the collection of new data on capabilities rather than achieved functionings, and their subsequent analysis.

\subsection{Policy Evaluation}

As an evaluative approach, the capability approach can also be used for both policy evaluations and policy design. However, in this area only limited applied research has been done. At the level of applied policy research, the UNDP [70] includes in its annual Human Development Report analyses of good practices of countries who have implemented policies that have enlarged people's capability sets, and gives a number of policy recommendations on how this could be done.

But it is also possible to apply the capability approach in a more scientific way to policy evaluation in micro-settings, for example when a local government redesigns the public infrastructure in a neighbourhood, or when a development NGO wants to evaluate its projects. Formally, and starting from the conversion function $\mathbf{b}_{i}=f_{i}\left(\mathbf{x}_{i}, \mathbf{z}_{i}\right)$, the change in functionings induced by policy implementation $\pi$ can be 
expressed as

$$
d \mathbf{b}_{i}=\underbrace{\frac{\partial f_{i}}{\partial \mathbf{x}_{i}} \frac{\partial \mathbf{x}_{i}}{\partial \pi} d \pi}_{a}+\underbrace{\frac{\partial \mathbf{f}_{i}}{\partial \mathbf{z}_{i}} \frac{\partial \mathbf{z}_{i}}{\partial \pi} d \pi}_{b}
$$

i.e. the policy has an impact on functionings through its impact on market and non-market resources $(a)$, but also through its impact on conversion factors (b). Thus, $a$ is akin to the traditional effect of a project on income, while $b$ is not recognised in traditional analysis.

Alkire [1] used the capability approach to evaluate functionings and capability-changes in three Oxfam poverty reduction projects in Pakistan: goat rearing, female literacy classes and rose garland production. A standard costbenefit analysis would evaluate the goat rearing project as a sound economic investment, with a number of nonquantifiable capability changes, such as the acquisition of useful knowledge and the cultivating of friendships. The capability evaluation of the goat rearing project has positive results both for the quantifiable and the intangible effects. The female literacy project, on the other hand, is a prime example of a project that would no longer be funded if it were evaluated only based on a standard cost-benefit analysis, as this project has hardly any effects on women's earnings, because there are no markets for female employment in this area of Pakistan. But Alkire found that it had a fundamental and transformative effect on the students, which cannot be quantified. These intangible effects include that they learn that women are equal to men, that they do not need to suffer abuse, that literate women can solve their own problems, that they learn how to read, and their subjective experience of great satisfaction at being able to study. The evaluation of the rose cultivation project also 
showed a contrast between the negative internal rate of return and a number of valuable non-economic intangible effects. Summing up, a standard welfare economic evaluation would conclude that the goat-rearing project dominates the literacy and the rose garland production projects, but from a capability perspective no project clearly dominates the other. Alkire concludes that "the choice cannot be made on technical grounds but rather is a morally significant choice" ([1]: 286)

\subsection{Conclusion}

From the above literature review we derive the following conclusions. Firstly, it is possible to measure welfare in terms of functionings. Second, welfare levels measured in terms of functionings differ significantly from those measured in terms of income or expenditure. As a consequence, rankings of welfare levels of countries and regions are different when they are performed according to standard welfare economics or the capability approach. In addition, not all who are income-poor are functionings poor and vice versa, which can have important implications for poverty reduction policies.

Our review also suggests that it is much more challenging to measure capabilities than functionings. For both the measurement of functionings and capabilities it holds that this literature is relatively recent and many of the applications are of an exploratory nature. Much more work needs to be done before a definite empirical assessment of the capability approach to welfare economics can be made. 


\section{Concluding Remarks}

In this paper we have characterised and analysed the capability approach from the perspective of standard welfare economics. We have argued that the capability approach entails profound critiques of the underlying assumptions of the standard welfare economic model. Taking on board these critiques can be done in two ways. Either one modifies the standard economic model to account for non-market goods and services, public and rationed goods, externalities, interpersonal heterogeneity and the intrinsic value of choice. Applied policy research in economics increasingly takes up this challenge, but poverty and inequality analysis has so far not sufficiently incorporated these concerns. The alternative strategy is to measure outcomes and opportunity directly, which is being advocated by the capability approach with its focus on functionings and capabilities. Interestingly, it is precisely inequality and poverty research in which welfare is increasingly measured in terms of functionings. Our survey of empirical applications suggests that welfare measurement in terms of functionings give complementary insights to the standard methods which focus on income and expenditures.

\section{References}

[1] Sabina Alkire. Valuing Freedoms: Sen's Capability Approach and Poverty Reduction. Oxford University Press, Oxford, 2002.

[2] Paul Anand and Martin van Hees. Capabilities and achievements: Models of survey evidence. mimeo, 2003. 
[3] Anthony B. Atkinson. The Contributions of Amartya Sen to Welfare Economics. Scandinavian Journal of Economics, 101(2):173-190, 1999.

[4] Anthony B. Atkinson and F. Bourguignon. The Comparison of Multi-Dimensioned Distribution of Economic Status. Review of Economic Studies, 49:183-201, 1982.

[5] Anthony B. Atkinson and F. Bourguignon. Income Distribution and Differences in Needs. In George F. Feiwel, editor, Arrow and the Foundations of the Theory of Economic Policy, pages 350-370. Macmillan Press, London, 1987.

[6] Anthony B. Atkinson and F. Bourguignon. Handbook of Income Distribution. Elsevier, Amsterdam, 2000.

[7] Anthony B. Atkinson and N.H. Stern. On Labour Supply and Commodity Commands. In Angus S. Deaton, editor, Essays in the Theory and Measurement of Consumer Behaviour in Honour of Sir Richard Stone, pages 265-296. Cambridge University Press, Cambridge, 1981.

[8] Alessandro Balestrino. A Note on Functionings Poverty in Affluent Societies. Notizei di Politeia, 12(43-44):97105, 1996.

[9] Alessandro Balestrino and Nicola Sciclone. Should we Use Functionings instead of Income to Measure Wellbeing? Theory, and some Evidence from Italy. mimeo, University of Pisa, 2000.

[10] Kaushik Basu and Luis F. López-Calva. Functionings and Capabilities. In Kenneth Arrow, Amartya Sen, and 
Kotaro Suzumura, editors, Handbook of Social Choice and Welfare, volume 2. Elsevier Science-North Holland, 2004.

[11] Gary S. Becker. A Theory of the Allocation of Time. Economic Journal, 75:493-517, 1965.

[12] Charles Bellemare, Bertrand Melenberg, and Arthur van Soest. Semiparametric Models for Satisfaction with Income. Portuguese Journal of Economics, 1:181-203, 2002 .

[13] Francois Bourguignon and Satya R. Chakravarty. Multi-dimensional Poverty Orderings. DELTA Working Paper, (22), 2002.

[14] Francois Bourguignon and Satya R. Chakravarty. The measurement of Multidimensional Poverty. Journal of Economic Inequality, 1, 2003.

[15] Andrea Brandolini and Giovanni D'Alessio. Measuring Well-Being in the Functioning Space. Paper presented in the Conference Justice and Poverty, examining Sen's capability approach, Cambridge, 5-7 June 2001, 1998.

[16] Martin Browning, Lars Peter Hansen, and James J. Heckman. Micro Data and General Equilbrium Models. In John B. Taylor and Michael Woodford, editors, Handbook of Macroeconomics, pages 543-633. North Holland, Amsterdam, 1999.

[17] Tania Burchardt and Julian Le Grand. Constraint and Opportunity: Identifying Voluntary Non-Employment. CASE Working Paper, (55), 2002.

[18] Frank A. Cowell. The Economics of Poverty and Inequality, volume 1. Edward Elgar, 2003. 
[19] Frank A. Cowell and Magda Mercader-Prats. Equivalence Scales and Inequality. In Jacques Silber, editor, Handbook of Income Inequality Measurement, pages 405-435. Kluwer Academic, Boston, Dordrecht and London, 1999.

[20] David Crocker. Functioning and Capabilities: The Foundation of Sen's and Nussbaum's Development Ethic. Political Theory, 20:584-612, 1992.

[21] Norman Daniels. Equality of What: Welfare, Resources, or Capabilities? Philosophy and Phenomenological Research, L:273-296, 1990.

[22] Bhaskar Dutta. Welfare Economics. Oxford University Press, 1994.

[23] Sakiko Fukuda-Parr. The Human Development Paradigm: Operationalising Sen's Ideas on Capabilities. Feminist Economics, 9(2-3):301-317, 2003.

[24] Alan M. Garber. Frontiers in Health Policy Research. MIT Press, 2001.

[25] Des Gasper. Sen's Capability Approach and Nussbaum's Capability Ethics. Journal of International Development, 9:281-302, 1997.

[26] Des Gasper. Is Sen's Capability Approach an Adquate Basis for Considering Human Development? Review of Political Economy, 14:435-460, 2002.

[27] Acharya Gayatri and Lynne Bennett. Valuing Open Space and Land-Use Pattern in Urban Watersheds. Journal of Real Estate Finance and Economics, 22(23):221-237, 2001. 
[28] Alissa Goodman, Paul Johnson, and Stephen Webb. Inequality in the UK. Oxford University Press, Oxford, 1997.

[29] W. Gorman. A Possible Procedure for Analyzing Quality Differentials in the Egg-Market. Review of Economic Studies, 47:843-856, 1980.

[30] Arnold Harberger. Project Evaluation: Collected Papers. Mac Millan, London, 1972.

[31] James J. Heckman. Accounting for Heterogeneity, Diversity and General Equilibrium in Evaluating Social Programs. NBER Working Paper: 7320, 1999.

[32] Joseph G. Hirschberg, Esfandiar Maasoumi, and Daniel J. Slottje. Clusters of Attributes and Well-Being in the USA. Journal of Applied Econometrics, 16:445460, 2001.

[33] Andrew Jones and Owen O'Donnell. Equivalence Scales and the Costs of Disability. Journal of Public Economics, 56(2):273-89, 1995.

[34] Stephan Klasen. Measuring Poverty and Deprivation in South Africa. Review of Income and Wealth, 46:33-58, 2000 .

[35] Wiebke Kuklys. Measurement and Determinants of Welfare Achievment - Evidence from the UK. mimeo, University of Cambridge, 2003.

[36] Wiebke Kuklys. A Monetary Approach to Capability Measurement of the Disabled - Evidence from the UK. Max Planck Institute for Research Into Economic Systems: Papers on Strategic Interaction, 2004. 
[37] Caterina Ruggeri Laderchi. Poverty and its many Dimensions: The Role of Income as an Indicator. Oxford Development Studies, 25(3):345-360, 1997.

[38] Caterina Ruggeri Laderchi. Do Concepts Matter? An Empirical Investigation of the Differences between a Capability and a Monetary Assessment of Poverty. Mimeo, University of Oxford, 2001.

[39] K. Lancaster. A New Approach to Consumer Theory. Journal of Political Economy, 74:132-157, 1966.

[40] Sara Lelli. Factor Analysis vs. Fuzzy Sets Theory: Assessing the Influence of Different Techniques on Sen's Functioning Approach. Center of Economic Studies Discussion Paper, KU Leuven, DPS 01.21, 2001.

[41] Esfandiar Maasoumi. The Measurement and Decomposition of Multi-Dimensional Inequality. Econometrica, 54(4):991-997, 1986.

[42] Esfandiar Maasoumi. Continuously Distributed Attributes and Measures of Multivariate Inequality. Journal of Econometrics, 42:131-144, 1989.

[43] Esfandiar Maasoumi. Multidimensioned Approaches to Welfare Analysis. In Jacques Silber, editor, Handbook of Income Inequality Measurement. Kluwer Academic, Boston, Dordrecht and London, 1999.

[44] Esfandiar Maasoumi and Gerald Nickelsburg. Multivariate Measures of Wellbeing and an Analysis of Inequality in the Michigan Data. Journal of Business and Economic Statistics, 6(3):327-334, 1988.

[45] Enrica Chiappero Martinetti. A Multidimensional Assessment of Well-Being Based on Sen's Functioning Ap- 
proach. Rivista Internazionale di Scienze Sociali, 2, 2000 .

[46] Mamta Murthi. Engel Equivalence Scales in Sri Lanka: exactness, specification, measurement error. In Richard Blundell, Ian Preston, and Ian Walker, editors, The Measurement of Household Welfare, pages 164-191. Cambridge University Press, Cambridge, 1994.

[47] Martha C. Nussbaum. Capabilities as Fundamental Entitlements: Sen and Social Justice. Feminist Economics, 9(2-3):33-59, 2003.

[48] Prasanta K. Pattanaik. Some Non-Welfaristic Issues in Welfare Economics. In Bhaskar Dutta, editor, Welfare Economics, pages 197-248. Oxford University Press, Oxford, 1994.

[49] Prasanta K. Pattanaik and Yongsheng Xu. On Ranking Opportunity Sets in Terms of Freedom of Choice. Recherches Economiques de Louvain, 56:383-390, 1990.

[50] Graham Hunter Paul Anand and Ron Smith. Capabilities and wellbeing: Evidence based on the sennussbaum approach to welfare. mimeo, 2003.

[51] Philip Pettit. Capability and Freedom: A Defence of Sen. Economics and Philosophy, 17:1-20, 2001.

[52] Shelley Phipps. The Well-Being of Young Canadian Children in International Perspective: A Functionings Approach. Review of Income and Wealth, 48(4):493, 2002.

[53] Robert A. Pollak and Terence J. Wales. Welfare Comparisons and Equivalence Scales. American Economic Review, Proceedings, 69:216-221, 1979. 
[54] Mozaffar Qizilbash. Capabilities, Well-Being and Human Development: A Survey. Journal of Development Studies, 36:143-162, 1996.

[55] Mozaffar Qizilbash. A Note on the Measurement of Poverty and Vulnerability in the South African Context. Journal of International Development, 14:757$772,2002$.

[56] Ingrid Robeyns. Gender Inequality. A Capability Perspective. PhD Thesis, University of Cambridge, 2002.

[57] Ingrid Robeyns. Sen's Capability Approach and Gender Inequality: Selecting Relevant Capabilities. Feminist Economics, 9(2-3):61-92, 2003.

[58] Erik Schokkaert and Luc Van Ootegem. Sen's Concept of the Living Standard Applied to the Belgian Unemployed. Recherches Economiques de Louvain, 56:429450, 1990.

[59] Amartya K. Sen. Collective Choice and Social Welfare. Holden Day, San Francisco, 1970.

[60] Amartya K. Sen. The Impossibility of a Paretian Liberal. Journal of Political Economy, 78:152-157, 1970.

[61] Amartya K. Sen. Personal Utilities and Public Judgments: or What's Wrong with Welfare Economics. Economic Journal, 89:537-558, 1979.

[62] Amartya K. Sen. Commodities and Capabilities. North Holland, Amsterdam, 1985.

[63] Amartya K. Sen. On the Foundations of Welfare Economics: Utility, Capability, and Practical Reason. In Francesco Farina and Stefano Vannucci, editors, 
Ethics, Rationality and Economic Behaviour, pages 5065. Clarendon Press, Oxford, 1996.

[64] Amartya K. Sen. Maximisation and the Act of Choice. Econometrica, 65(4):745-779, 1997.

[65] Amartya K. Sen. Social Justice and Distribution of Income. In A.B. Atkinson and F. Bourguignon, editors, Handbook of Income Inequality, pages 59-86. North Holland, Amsterdam, 2000.

[66] Amartya K. Sen. Development as capability expansion. In Sakiko Fukuda-Parr and A.K. Shiva Kumar, editors, Readings in Human Development. Concepts, Measures and Policies for a Development Paradigm, pages 3-16. Oxford University Press, 2003.

[67] George J. Stigler and Gary S. Becker. De Gustibus Non Est Disputandum. American Economic Review, 67:76-90, 1977.

[68] Kotaro Suzumura. Introduction. In Kenneth Arrow, Amartya Sen, and Kotaro Suzumura, editors, Handbook of Social Choice and Welfare, volume 1, pages 1-94. Elsevier Sciences - North Holland, 2002.

[69] Kenneth E. Train, Andrew Goett, and Kathleen Hudson. Customer choice among retail energy suppliers: The willingness to pay for service attributes. Energy Journal, 21(4):109-129, 2000.

[70] UNDP. Human Development Report. Oxford University Press, Oxford, 1990-2002.

[71] Andrew Williams. Dworkin on Capability. Ethics, 113(1):23-39, 2002. 
[72] Asghar Zaidi and Tania Burchardt. Comparing Incomes when Needs Differ: Equivalisation for the Extra Cost of Disability in the UK. CASE Working Paper, (64), 2003. 
Table 1: Review of Welfare Measurement Studies

\begin{tabular}{llc}
\hline \hline Author & Datasets & Manctionings \\
& & \\
\hline
\end{tabular}

Functionings: national/regional comparisons

\begin{tabular}{|c|c|c|c|}
\hline Sen $([62]: 46-51)$ & $\begin{array}{l}\text { Brazil, China, India, } \\
\text { Mexico, Sri Lanka } \\
(1980-1982)\end{array}$ & $\begin{array}{l}\text { Life expectancy, infant mortality, } \\
\text { child death rates }\end{array}$ & $\begin{array}{l}\text { Country rankings based on GNP per capita } \\
\text { differ from rankings based on functionings. }\end{array}$ \\
\hline Sen $([62]: 52-69)$ & India (1981-1983) & Mortality, nutrition, morbidity & $\begin{array}{l}\text { Women have worse functionings outcomes } \\
\text { than men. }\end{array}$ \\
\hline UNDP $[70]$ & $\begin{array}{l}\text { Data at national level, all } \\
\text { countries }\end{array}$ & $\begin{array}{l}\text { Life expectancy at birth, educa- } \\
\text { tion, material welfare (GNP per } \\
\text { capita) }\end{array}$ & $\begin{array}{l}\text { Country rankings based on GNP per capita } \\
\text { differ from rankings based on functionings in- } \\
\text { dices; each year the UNDP focuses on one area } \\
\text { of functioning wellbeing and discusses best } \\
\text { practices for policies. }\end{array}$ \\
\hline $\begin{array}{l}\text { Balestrino and } \\
\text { Sciclone }[9]\end{array}$ & $\begin{array}{l}\text { Provincial level data for } \\
\text { Italy (1991) }\end{array}$ & $\begin{array}{l}\text { Being healthy, educated, em- } \\
\text { ployed, living in a comfortable } \\
\text { house, in a safe area and in a non- } \\
\text { polluted environment }\end{array}$ & $\begin{array}{l}\text { Rankings of regions based on functionings and } \\
\text { gross regional product per capita correlated } \\
\text { strongly, but rankings differ for } 7 \text { out of } 20 \\
\text { regions. }\end{array}$ \\
\hline Quizilbash [55] & $\begin{array}{l}\text { Provincial level data } \\
\text { from the South African } \\
\text { Census }\end{array}$ & $\begin{array}{l}\text { Education, access to water, refuse } \\
\text { removal, cooking facilities, rooms } \\
\text { per household and employment }\end{array}$ & $\begin{array}{l}\text { Expenditures poverty versus functionings } \\
\text { poverty rankings of the nine provinces differ } \\
\text { significantly. }\end{array}$ \\
\hline
\end{tabular}


Table 1 continued

\begin{tabular}{llc}
\hline \hline Author & Datasets & Main findings and Policy Conclusions \\
& & \\
\hline
\end{tabular}

\section{Functionings: micro analysis}

Schokkaert and Survey among Belgian Van Ootegem unemployed (1979)

Balestrino ([8])

281 Italian households officially registered as poor

Ruggeri Lader- Chile (1992)

$\operatorname{chi}([37])$

Ruggeri Lader-

chi $([38])$

\section{ENNIV Survey, Peru Education, health}

Social functioning, psychological functioning, physical functioning, micro-social contact, activity lev-

els, financial functioning

Education, nutrition, health

Education, health, child nutrition

Income variables are an insignificant determinant of shortfall in all three functionings

In order to achieve a higher overlap between analyses based on monetary welfare measures and functionings, the monetary poverty line has to be significantly increased. $22.8 \%$ of the stunted children and $22.4 \%$ of the children 12 -

15 years old with less than 5 years of schooling are not financially poor. 


\begin{tabular}{llc}
\hline \hline Author & Datasets & Main findings and Policy Conclusions \\
& & \\
\hline
\end{tabular}

\section{Functionings: micro analysis continued}

\begin{tabular}{|c|c|c|c|}
\hline Phipps [52] & $\begin{array}{l}\text { Children Surveys for } \\
\text { Canada, Norway and } \\
\text { USA (1995) }\end{array}$ & $\begin{array}{l}\text { Low birth weight, asthma, acci- } \\
\text { dents, activity limitation trouble } \\
\text { concentrating, anxiety, disobedi- } \\
\text { ence at school, bullying }\end{array}$ & $\begin{array}{l}\text { The functionings wellbeing of Canadian and } \\
\text { US children cannot be unambiguously ranked, } \\
\text { but Norwegian children fare better than either } \\
\text { of them. }\end{array}$ \\
\hline $\begin{array}{l}\text { Chiappero Mar- } \\
\text { tinetti }[45]\end{array}$ & $\begin{array}{l}\text { Italian Household Survey } \\
(1994)\end{array}$ & $\begin{array}{l}\text { Housing, health, education, so- } \\
\text { cial interactions, psychological } \\
\text { wellbeing }\end{array}$ & $\begin{array}{l}\text { Women, elderly, people living in the South of } \\
\text { Italy, housewives and blue-collar workers have } \\
\text { lower functionings achievements than other } \\
\text { groups. }\end{array}$ \\
\hline Klasen [34] & $\begin{array}{l}\text { SALDRU } \text { Household } \\
\text { Surevey, South Africa } \\
(1994)\end{array}$ & $\begin{array}{l}\text { Education, income, wealth, hous- } \\
\text { ing, water, sanitation, energy, } \\
\text { employment, transport, financial } \\
\text { services, nutrition, health care, } \\
\text { safety, perceived wellbeing }\end{array}$ & $\begin{array}{l}\text { Some groups are much deeper functionings de- } \\
\text { prived than suggested by the expenditure mea- } \\
\text { surement; } 17 \% \text { of the people who are function- } \\
\text { ings deprived are not identified as poor by the } \\
\text { expenditure index. }\end{array}$ \\
\hline Lelli [40] & $\begin{array}{l}\text { Panel Study of Belgian } \\
\text { Households (1998) }\end{array}$ & $\begin{array}{l}\text { Psychological wellbeing, social } \\
\text { interactions, economic condi- } \\
\text { tions, cultural activities, working } \\
\text { conditions, shelter, health }\end{array}$ & $\begin{array}{l}\text { Detailed description of welfare differences } \\
\text { among the Belgian population. Correlations } \\
\text { between functionings and income are low, with } \\
\text { absolute values ranging befrom } 0.02 \text { to } 0.39 \text {. }\end{array}$ \\
\hline
\end{tabular}


Table 1 continued

\begin{tabular}{|c|c|c|c|}
\hline Author & $\overline{\text { Datasets }}$ & Functionings & Main findings and Policy Conclusions \\
\hline \multicolumn{4}{|c|}{ Capabilities: micro analysis } \\
\hline $\begin{array}{l}\text { Burchardt and } \\
\text { LeGrand [17] }\end{array}$ & BHPS (1998-1999) & Being employed & $\begin{array}{l}\text { The capability to be employed is identified by } \\
\text { testing whether a person's being unemployed } \\
\text { is the outcome of a decision by herself ( } 10 \% \\
\text { of the unemployed) or due to constraints she } \\
\text { faces. }\end{array}$ \\
\hline $\begin{array}{l}\text { Anand and van } \\
\text { Hees [2] }\end{array}$ & $\begin{array}{l}273 \text { individuals in Eng- } \\
\text { land (2001) }\end{array}$ & $\begin{array}{l}\text { Happiness, general achievement, } \\
\text { health, intellectual stimulation, } \\
\text { social relations, environmental } \\
\text { quality, personal integrity }\end{array}$ & $\begin{array}{l}\text { Income is negatively correlated with self- } \\
\text { reported overall capability levels. High pos- } \\
\text { itive correlations between self-reported capa- } \\
\text { bilities and achievements. }\end{array}$ \\
\hline
\end{tabular}

